\title{
3-Hidroksipiridin-4-oni (I. dio): Priprava i kelirajući učinak
}

DOI: $10.15255 / K U I .2015 .050$

KUI-40/2016

Pregledni rad

Prispjelo 15. prosinca 2015.

Prihvaćeno 1. veljače 2016 .

\section{Ž. Car, V. Petrović Peroković i S. Tomić Pisarović}

Zavod za organsku kemiju, Kemijski odsjek, Prirodoslovno-matematički fakultet, Sveučilište u Zagrebu, Horvatovac 102A, 10000 Zagreb

\section{|| Sažetak}

Od otkrića deferiprona 1982. godine, za sada jedinog 3-hidroksipiridin-4-onskog kelatora tvrdih metalnih iona koji je prošao klinička ispitivanja, ti su heterociklički derivati postali iznimno proučavana skupina spojeva. U radu su opisana dva najčešća načina priprave osnovne heterocikličke 3-hidroksipiridin-4-onske strukture, a to su Harrisova metoda i izravni postupak. Osim toga, dan je pregled važnijih fizikalno-kemijskih parametara potrebnih za preliminarnu evaluaciju kelirajućeg učinka dobivenih derivata.

\section{\| Ključne riječi}

3-hidroksipiridin-4-oni, izravna sinteza, Harrisova metoda, željezo(III), kelator, fizikalno-kemijska svojstva

\section{Uvod}

Hidroksipiridinoni (HP, slika 1) su heterociklički, polifunkcionalni spojevi koji se, s obzirom na položaj hidroksilne i keto-skupine u odnosu na dušikov atom u prstenu, uobičajeno dijele na: 1-hidroksipiridin-2-one (1,2-HP), 3-hidroksipiridin-2-one (3,2-HP) i 3-hidroksipiridin-4-one (3,4HP). HP su bidentatni ligandi metalnih iona u području fiziološkog pH što je osnova njihova raznolikog biološkog djelovanja. Velik broj patoloških stanja uzrokovanih poremećajem u metabolizmu biološki važnih metala, bilo kao posljedica genskog poremećaja ili pretjeranog izlaganja štetnom vanjskom utjecaju, može se liječiti ili barem ublažiti djelovanjem kelirajućih agenasa. U tom smislu, derivati HP istražuju se ponajprije kao agensi za uklanjanje iona metala, ali i kao antibakterijski i antitumorski agensi te kao potencijalni antimalarici i antidementici. ${ }^{1-3}$ Sintetski se najčešće modificiraju uvođenjem supstituenata na različite položaje njihove osnovne heterocikličke strukture, pri čemu se vezno mjesto za ione metala, koje čine kisikovi atomi hidroksilne i keto-skupine, ne modificira ili privremeno zaštiti. Sintetskim se modifikacijama utječe na njihova fizikalno-kemijska te farmakološka svojstva (netoksičnost i mogućnost oralne primjene liganda, lipo-hidrofilna ravnoteža, učinkovita biodostupnost na ciljana mjesta u organizmu, uklanjanje kompleksa putem urina i/ili žuči), a time i potencijalno biološko djelovanje.

Hidroksipiridinoni 3,4-HP posebno su zanimljivi jer su se pokazali učinkovitijim kelatorima trovalentnih, tvrdih metalnih iona, primjerice $\mathrm{Fe}(\mathrm{III})$ i $\mathrm{Al}(\mathrm{III})$, u fiziološkim uvjetima u odnosu na ostale HP-derivate. $U$ tablici 1 prikazane su logaritamske vrijednosti ukupnih konstanti stabilnosti kompleksa HP-liganada sa željezom (kompleksi sastava<smiles>O=c1ccccn1O</smiles>

$1,2-\mathrm{HP}$<smiles>[R]n1cccc(O)c1=O</smiles>

$3,2-\mathrm{HP}$<smiles>[R]c1c(O)c(=O)ccn1[R]</smiles>

$3,4-\mathrm{HP}$

$$
\begin{array}{ll}
\mathrm{R}^{1}=\text { alkil } & \mathrm{R}^{1}=\text { alkyl } \\
\mathrm{R}=\text { alkil, aril } & \mathrm{R}=\text { alkyl, aryl }
\end{array}
$$

Slika 1 - Derivati hidroksipiridinona

Fig. 1 - Hydroxypyridinone derivatives

ligand: $\mathrm{Fe}(\mathrm{III})=3: 1)$ koje su rezultat niza kombiniranih potenciometrijskih i spektrofotometrijskih analiza serije tih derivata. ${ }^{4}$ Osim što stvaraju stabilnije komplekse $s$ Fe(III), derivati 3,4-HP pokazuju visok afinitet i selektivnost prema tim metalima u odnosu na ostale biološki važne dvovalentne ione poput $\mathrm{Cu}(\mathrm{II}), \mathrm{Zn}(\mathrm{II}), \mathrm{Fe}(\mathrm{II})$ i drugih (tablica 2$){ }^{4}$

Tablica 1 - Logaritamske vrijednosti ukupnih konstanti stabilnosti za komplekse Fe(III) s HP-derivatima (Fe(III) : HP $=1: 3)^{4}$

Table 1 - Logarithmic values of overall stability constants for complexes of $\mathrm{Fe}(\mathrm{III})$ with $\mathrm{HP}$ derivatives (Fe(III) : HP $=1: 3)^{4}$

\begin{tabular}{c|c}
\hline Ligand & $\log \beta_{3}$ \\
\hline $1,2-\mathrm{HP}$ & 27 \\
$3,2-\mathrm{HP}$ & 32 \\
$3,4-\mathrm{HP}$ & 37 \\
\hline
\end{tabular}


3-Hidroksi-1,2-dimetilpiridin-4-on (deferipron, Ferriprox ${ }^{\circledR}$, slika 2a) jedan je od najpoznatijih predstavnika te klase spojeva. U kliničkoj je upotrebi kao sredstvo za keliranje željeza u osoba kod kojih je došlo do prekomjernog nakupljanja željeza u organizmu. Poremećaj u metabolizmu tog metala javlja se najčešće kao posljedica određene bolesti kao što je, primjerice, nasljedna (primarna) hemokromatoza, genetsko oboljenje koje rezultira pojačanim nakupljanjem željeza u organima. Druga skupina nasljednih genetskih oboljenja pod nazivom talasemije može u konačnici dovesti do stečene (sekundarne) hemokromatoze. Ljudi oboljeli od težih oblika talasemije podvrgavaju se čestim transfuzijama krvi što vodi do povećane koncentracije tog metala u organizmu. Unazad 50 godina se kao kelator željeza najviše upotrebljavala prirodna siderofora iz Streptomyces pilosus, desferioksamin B u obliku mesilatne soli (DFO, Desferal ${ }^{\circledR}$, slika 2b) kao jedini klinički lijek u tu svrhu. ${ }^{1}$

Tablica 2 - Logaritamske vrijednosti konstanti stabilnosti kompleksa 3,4-HP odnosno desferioksamina B s različitim ionima metala ${ }^{4}$

Table 2 - Logarithmic values of stability constants for complexes of 3,4-HP or desferrioxamine B with various metal ions $^{4}$

\begin{tabular}{ccc}
\hline $\mathrm{M}^{\mathrm{n}+}$ & $\log \beta$ (DFO) & $\log \beta_{\mathrm{n}}(3,4-\mathrm{HP})$ \\
\hline $\mathrm{Fe}^{3+}$ & 31 & 37 \\
$\mathrm{Cu}^{2+}$ & 14 & 17 \\
$\mathrm{Zn}^{2+}$ & 11 & 12,5 \\
$\mathrm{Mg}^{2+}$ & 4 & 7 \\
$\mathrm{Ca}^{2+}$ & 2,5 & 4,5 \\
\hline
\end{tabular}

Glavni nedostatak DFO-a jest njegova inaktivnost kada se primjenjuje oralno te se mora primjenjivati intravenozno, što pacijenti zajedno s brojnim i dugotrajnim transfuzijama krvi dosta teško podnose. Derivati 3,4-HP su prema svojim fizikalno-kemijskim i farmakološkim parametrima vrlo dobri kandidati za keliranje željeza in vivo ali i oralnu primjenu, te se u tu svrhu najviše istražuju.

U ovome će se radu dati literaturni pregled metoda primjenjivanih za sintezu osnovne heterocikličke strukture 3,4HP. Reakcijski uvjeti, kao i struktura reaktanata potrebnih za pripravu 3,4-HP te umjereni prinosi prikazanih sinteza posljedica su reakcijskog mehanizma koji će također biti pobliže opisan. Dodatno, selektivnost tih spojeva prema trovalentnim metalnim ionima pokušat će se objasniti kroz analizu njihovih fizikalno-kemijskih svojstava u otopini. Sinteza tih derivata u svrhu njihove biološke evaluacije, predmet su istraživanja koja se posljednjih godina, među ostalim, provode i u našem laboratoriju. ${ }^{5-8}$

\section{Sinteza osnovne heterocikličke strukture 3,4-HP}

U literaturi je opisano nekoliko postupaka sinteze osnovnog skeleta 3,4-HP. Metoda po Harrisu9 (shema 1, tablica 3) može se primjenjivati za sintezu $\mathrm{N}$-alkilnih i $\mathrm{N}$-arilnih 3,4-HP spojeva iz komercijalno dostupnih piranonskih derivata, maltola $\left(\mathrm{R}^{1}=\mathrm{CH}_{3}\right)$ ili etilmaltola $\left(\mathrm{R}^{1}=\mathrm{CH}_{2} \mathrm{CH}_{3}\right)$. Prvi korak te metode podrazumijeva uvođenje eterske zaštite, najčešće benzilne, na skupinu 3-OH polaznog piran-4ona, nakon čega $\mathrm{u}$ drugom koraku u reakciji s primarnim aminom nastaje zaštićeni 3,4-HP derivat, koji se u konačnici deprotektira hidrogenolizom (treći korak). U tablici 3 dan je literaturni pregled reakcijskih uvjeta te prinosa za Harrisovu metodu priprave osnovne piridinonske strukture.

Može se uočiti da razlika u reakcijskim uvjetima u kojima se provodi drugi korak ovisi o strukturi aminskog derivata koji se upotrebljava kao nukleofil. Ako su nukleofili alifatski amini, drugi se korak obično provodi u alkoholno-vodenim otapalima uz refluks. U slučaju aromatskih amina često se primjenjuju postupci bez dodatka otapala uz zagrijavanje na nešto višim temperaturama $\left(\approx 120{ }^{\circ} \mathrm{C}\right)$

a)<smiles>Cc1c(O)c(=O)ccn1C</smiles>

b)<smiles>CC(=O)N(O)CCCCCNC(=O)CCC(=O)N(O)CCCCCNC(=O)CCC(=O)N(O)CCCCCN</smiles>

Slika 2 - Strukturne formule: a) deferiprona; b) Desferala ${ }^{\circledR}$ Fig. 2 - Structural formulas of: a) deferiprone; b) Desferal ${ }^{\circledR}$ 


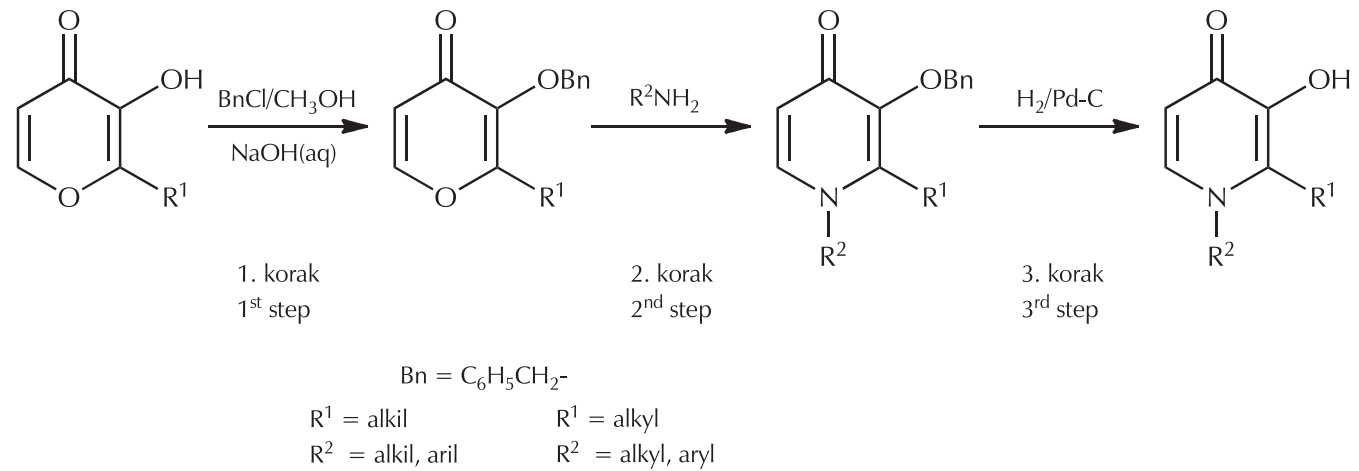

Shema 1 - Priprava N-supstituiranih derivata 3,4-HP metodom po Harrisu

Scheme 1 - The Harris method used for the preparation of N-substituted 3,4-HP derivatives

Tablica 3 - Reakcijski uvjeti i prinosi Harrisove metode priprave derivata 3,4-HP

Table 3 - Reaction conditions and yields in synthesis of 3,4-HP derivatives by Harris method

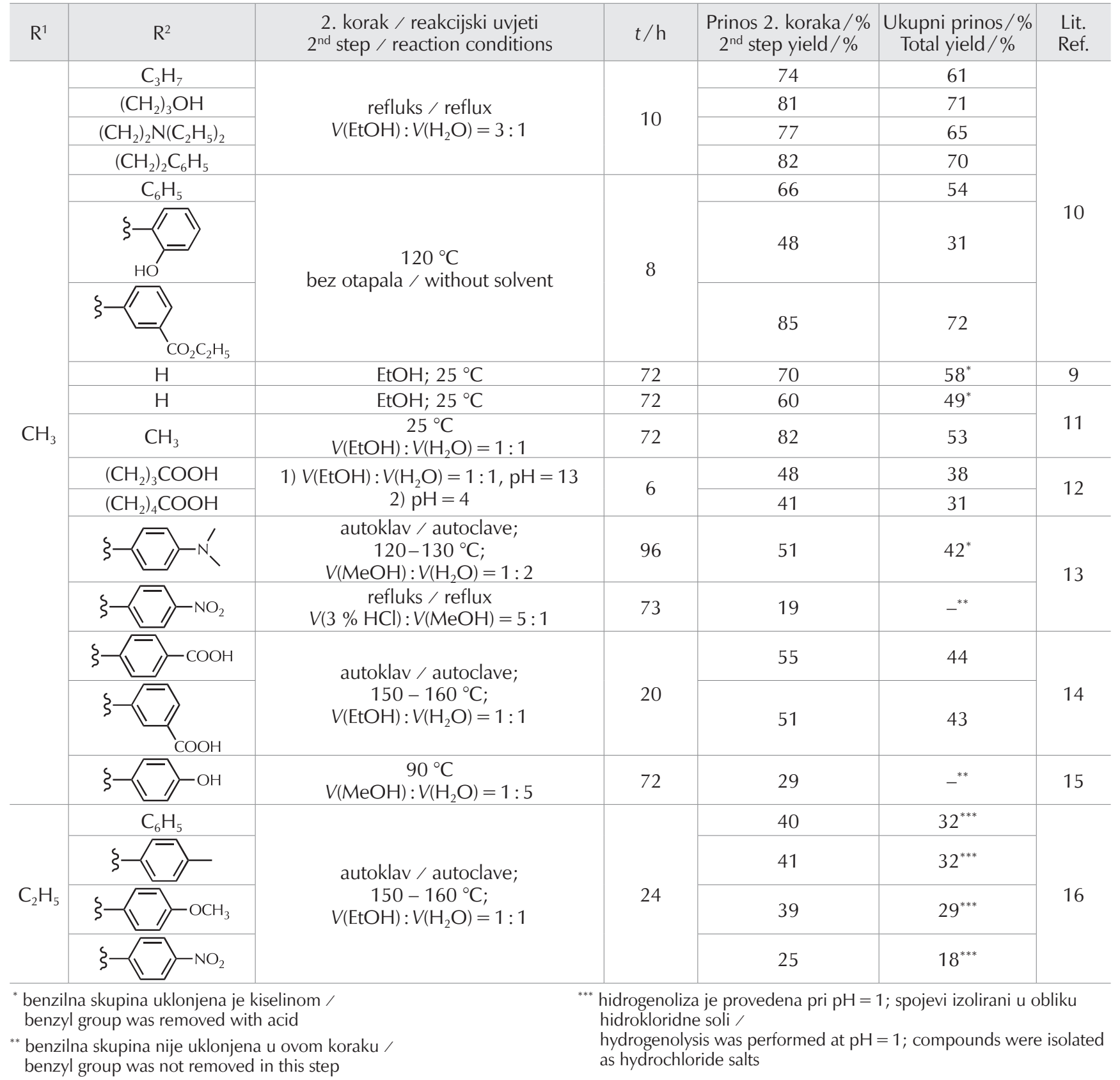


ili se komponente zagrijavaju u zatvorenim sustavima (autoklav, $\approx 150{ }^{\circ} \mathrm{C}$ ). Razlog tome su drugačija fizikalna svojstva aromatskih u odnosu na alifatske amine, konkretno više temperature vrelišta ili tališta te činjenica da im je topljivost u vodi ili alkoholno-vodenim sredinama, u kojima se obično drugi korak Harrisova pristupa provodi, relativno slaba.

Druga metoda, koja se pretežno primjenjuje za pripravu $N$-arilnih derivata 3,4-HP, poznata i kao izravna metoda, podrazumijeva zagrijavanje nezaštićenog piranonskog derivata i odgovarajućeg arilamina. Reakcije se uobičajeno provode u jednome koraku (shema 2) s dodatkom kiselog katalizatora ili bez kiselog katalizatora, najčešće Brønstedovih kiselina $\left(\mathrm{HCl}, \mathrm{H}_{2} \mathrm{SO}_{4}, p-\mathrm{TsOH}\right)$, uz refluks ili u autoklavu. ${ }^{8,17-20}$

Uspoređivanjem obje opisane metodologije uočava se da je Harrisov pristup, u kojem se drugi reakcijski korak provodi klasičnim zagrijavanjem u smjesi otapala alkohol/ voda, najučinkovitiji način priprave $N$-alkilnih derivata 3,4-HP. Postupci priprave tih derivata provedeni bez prethodnog zaštićivanja hidroksilne skupine polaznog piranona u literaturnim navodima iznimno su rijetko opisani te je poznato da jedino u slučaju kratkolančanih alifatskih amina kao reaktanata rezultiraju zadovoljavajućim prinosom. ${ }^{21} \mathrm{U}$ sintezi $\mathrm{N}$-arilnih derivata 3,4-HP zagrijavanje u autoklavu ili postupci koji se provode bez dodatka otapala optimalniji su zbog kraćih reakcijskih vremena (8 - 40 h) u odnosu na klasični način zagrijavanja reaktanata u otapalu uz dodatak katalizatora (shema 2; 50 - 72 h). Općenito se može primijetiti da su za većinu opisanih reakcija karakteristični umjereni do niski prinosi, dugotrajnost te visoke temperature pri kojima se one provode. S druge strane, glavna prednost opisanih sinteza jest da se temelje na jeftinom te lako dostupnom polaznom materijalu.

Poznavanje mehanizma stvaranja strukture 3,4-HP olakšava odabir postupka priprave željenog derivata 3,4-HP. Radi se o dvostrukoj nukleofilnoj konjugiranoj adiciji Michaelova tipa na položaje C-2 i C- $6 \alpha, \beta$-nezasićenog karbonilnog piranonskog derivata, pri čemu su nukleofili odgovarajući alkil- ili arilamini (shema 3). U tako bazičnom mediju, pogotovo kada se radi s razgranatim alkilaminima $\left(\mathrm{p} K_{\mathrm{aH}} \approx 11-12\right)$, pogodno je zaštititi hidroksilnu skupinu piranona $\left(\mathrm{p} K_{\mathrm{a}}=8,44\right.$ za maltol $^{22}$ ), jer je u protivnom moguće njezino deprotoniranje i stvaranje kompetirajućeg nukleofila, alkoksida. To u konačnici vodi k nastanku kondenzacijskih nusprodukata (shema 4) te smanjenom prinosu reakcije. Kada se reakcije provode s manje bazičnim arilaminima, konverziju piranonskog derivata moguće je provesti i bez zaštite njegove hidroksilne skupine, odnosno izravnim postupkom. Štoviše, u tim slučajevima se pokazalo da je dodatak kiselog katalizatora dovoljan da bi se smanjila mogućnost nastanka alkoksida i spriječila sporedna reakcija. Utjecaj kiselog katalizatora posebno je došao do izražaja u pripravi 3-hidroksi-2-metil-1-(p-nitrofenil)piridin-4-ona ( $p$-nitrofenil-supstituirani 3,4-HP) u izravnoj sintezi u autoklavu (shema 2a) koju su proveli Jakopčić i sur. ${ }^{17} \mathrm{U}$ nekataliziranoj reakciji produkt nastaje

u tragovima, dok je prinos reakcije $47 \%$ ako se u sintezi upotrebljavaju katalitičke količine $p$ - $\mathrm{TsOH}$ ili $\mathrm{H}_{2} \mathrm{SO}_{4}$.

Budući da se kao polazne piranonske strukture obično upotrebljavaju maltol i etil-maltol, nešto niži prinosi reakcija primijećeni su u slučaju etil-maltola, što se objašnjava većim steričkim smetnjama prilikom ciklizacije i formiranja piridinonskog prstena nakon nukleofilnog napada amina.

Prinosi opisanih reakcija priprave N-arilnih 3,4-HP u skladu su i s elektronskim svojstvima skupina koje se nalaze u para-položaju na polaznim anilinskim derivatima. Sinteze u kojima se upotrebljavaju nukleofilniji anilinski derivati tj. oni s elektron-donirajućim supstituentima, prema očekivanjima, rezultiraju višim prinosima. Tako će primjerice reakcija u kojoj je nukleofil p-metoksianilin rezultirati većim prinosom u odnosu na reakciju provedenu s $p$-nitroanilinom, kao što se može jasno vidjeti iz izravnog postupka priprave $\mathrm{N}$-arilnih 3,4-HP prikazanog na shemi $2 \mathrm{a}$.<smiles>[R]c1ccc(-n2ccc(=O)c(O)c2[R])cc1CC</smiles>

a)

$\mathrm{R}^{2}=\mathrm{CH}_{3} ; \mathrm{R}^{3}=\mathrm{H}$

\begin{tabular}{c|c}
\hline $\mathrm{R}^{1}$ & $\begin{array}{c}\text { prinos } / \% \\
\text { yield } / \%\end{array}$ \\
\hline $\mathrm{H}$ & 35 \\
$\mathrm{CH}_{3}$ & 42 \\
$\mathrm{NO}_{2}$ & $47^{*}$ \\
$\mathrm{Cl}$ & 66 \\
$\mathrm{OCH}_{3}$ & 56 \\
$\mathrm{OC}_{2} \mathrm{H}_{5}$ & 74
\end{tabular}

${ }^{*} \mathrm{~s}$ katalizatorom (p- $\mathrm{TsOH}$ ili $\mathrm{H}_{2} \mathrm{SO}_{4}$ ) with catalyst $\left(p-\mathrm{TsOH}_{\mathrm{S}}\right.$ or $\mathrm{H}_{2} \mathrm{SO}_{4}$ )

\begin{tabular}{c|c|c|c}
\hline $\mathrm{R}^{1}$ & $\mathrm{R}^{2}$ & $\mathrm{R}^{3}$ & $\begin{array}{c}\text { prinos } / \% \\
\text { yield } \%\end{array}$ \\
$\mathrm{H}$ & $\mathrm{CH}_{3}$ & $\mathrm{H}$ & $22,35,55^{*}$ \\
$\mathrm{H}$ & $\mathrm{CH}_{3}$ & $\mathrm{Cl}$ & 11 \\
$\mathrm{H}$ & $\mathrm{CH}_{3}$ & $\mathrm{OH}$ & 15,40 \\
$\mathrm{H}$ & $\mathrm{CH}_{3}$ & $\mathrm{COOH}$ & 43 \\
$\mathrm{COOH}$ & $\mathrm{CH}_{3}$ & $\mathrm{H}$ & 20 \\
$\mathrm{OCH}_{3}$ & $\mathrm{CH}_{3}$ & $\mathrm{H}$ & 58 \\
$\mathrm{H}^{2}$ & $\mathrm{C}_{2} \mathrm{H}_{5}$ & $\mathrm{H}$ & $<10$ \\
$\mathrm{CH}_{3}$ & $\mathrm{CH}_{3}$ & $\mathrm{H}$ & $52^{*}$ \\
$\mathrm{NO}_{2}$ & $\mathrm{CH}_{3}$ & $\mathrm{H}$ & $28^{*}$ \\
$\mathrm{NH}_{2}$ & $\mathrm{CH}_{3}$ & $\mathrm{H}$ & $42^{*, * *}$ \\
$\left.\mathrm{CH}^{*} \mathrm{CH}_{3}\right)$ & $\mathrm{CH}_{3}$ & $\mathrm{H}$ & $23(R+S)$ \\
$\mathrm{CH}_{2} \mathrm{CH}_{3}$ & & & \\
\hline
\end{tabular}

" bez organskog otapala / without organic solvent

** bez katalizatora, $120 \mathrm{~h}$ / without catalyst, $120 \mathrm{~h}$

Shema 2 - Izravni pristup priprave $\mathrm{N}$-arilnih 3,4-HP s dodatkom kiselog katalizatora ili bez dodatka kiselog katalizatora: a) autoklav, $\mathrm{H}_{2} \mathrm{O}, 150{ }^{\circ} \mathrm{C}, 40 \mathrm{~h} ;{ }^{17}$ b) $\mathrm{MeOH}$ ili $\mathrm{EtOH}, \mathrm{HCl}(\mathrm{aq})$, refluks, $50-72 \mathrm{~h}^{8,18-20}$

Scheme 2 - Synthesis of N-aryl 3,4-HP with or without acid catalyst - the direct approach: a) autoclave, $\mathrm{H}_{2} \mathrm{O}$, $150{ }^{\circ} \mathrm{C}, 40 \mathrm{~h} ; i^{17}$ b) $\mathrm{MeOH}$ or $\mathrm{EtOH}, \mathrm{HCl}(\mathrm{aq})$, reflux, $50-72 \mathrm{~h}^{8,18-20}$ 
<smiles>[Y]C1=C(O)C(O)=CC(N([Y2])[CH]C(C)C)O1</smiles>

$$
\begin{array}{ll}
\mathrm{R}^{1}=\text { alkil } & \mathrm{R}^{1}=\text { alkyl } \\
\mathrm{R}^{2}=\text { alkil, aril } & \mathrm{R}^{2}=\text { alkyl, aryl }
\end{array}
$$

Shema 3 - Mehanizam konverzije piranonskog prstena u strukturu 3,4-HP16,18

Scheme 3 - Reaction mechanism for the conversion of a pyranone ring into 3,4-HP structure ${ }^{16,18}$<smiles></smiles>

Shema 4 - Sporedna reakcija i stvaranje kondenzacijskih nusprodukata u bazičnim uvjetima priprave derivata 3,4-HP18 Scheme 4 - Side reaction and the condensation by-product formation in basic conditions in 3,4-HP synthesis ${ }^{18}$

Utjecaj vrste kiselog katalizatora na prinos produkta te optimalno vrijeme trajanja reakcije ispitano je na primjeru priprave jednog $\mathrm{N}$-arilnog derivata, 3-hidroksi-2-metil-1-(p-metoksifenil)piridin-4-ona (shema 5) izravnom metodom u autoklavu. ${ }^{6}$ Rezultati su pokazali da reakcija koja je provedena uz $p$-TsOH već nakon 24 h rezultira nešto većim prinosom (63 \%) u odnosu na nekataliziranu reakciju ${ }^{17}(40$ h, $56 \%$, shema $2 a)$. Nadalje, pokazalo se da produljenje vremena reakcije ne utječe bitno na prinos produkta. Kada se upotrebljava $\mathrm{HCl}$ kao katalizator, do povećanja prinosa u odnosu na nekataliziranu reakciju ne dolazi niti nakon $48 \mathrm{~h}$. Takvim izravnim načinom priprave uz obvezatan dodatak $p$ - $\mathrm{Ts} \mathrm{OH}$ kao katalizatora moguće je pripraviti različite $\mathrm{N}$-arilne derivate $3,4-\mathrm{HP}$ te ih potom dodatno modificirati prema vrsti biološkog učinka koji se želi ispitati. ${ }^{5,7}$ 


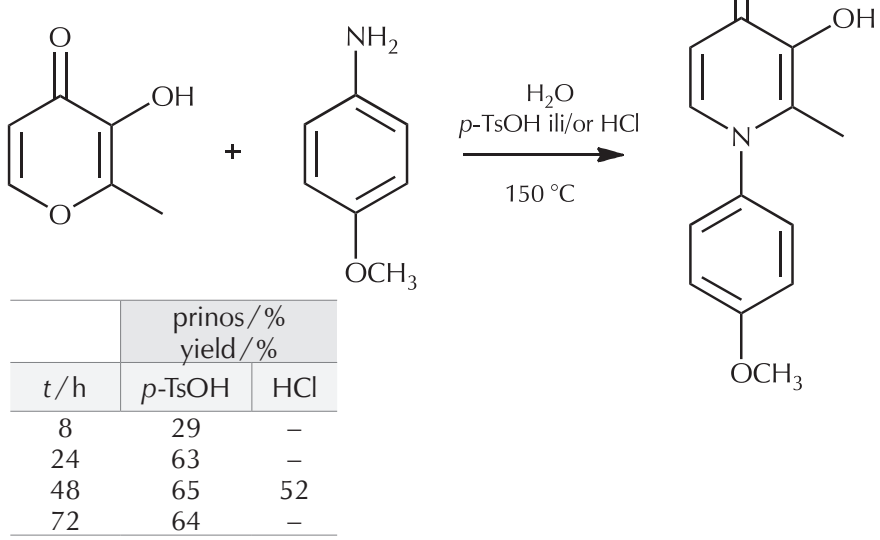

Shema 5 - Optimalno reakcijsko vrijeme i utjecaj promjene katalizatora na prinos izravne metode priprave 3-hidroksi-2-metil-1-( $p$-metoksifenil)piridin-4-ona ${ }^{7}$

Scheme 5 - Optimal reaction time and the influence of acid catalyst on reaction yields in the direct synthesis of 3-hydroxy-1-(p-methoxyphenyl)-2-methylpyridin-4-one ${ }^{7}$

\section{Važniji fizikalno-kemijski parametri i metode za evaluaciju kelatora}

Kao što je već spomenuto, 3,4-HP pokazuju visok afinitet ali i selektivnost prema trovalentnim, tvrdim ionima metala, primjerice $\mathrm{Fe}(\mathrm{III})$ i $\mathrm{Al}(\mathrm{III})$, u odnosu na ostale biološki važne dvovalentne ione. Upravo to je glavni razlog zašto se ta vrsta spojeva danas istražuje ponajprije u svrhu uklanjanja viška navedenih metala iz organizma odnosno kao potencijalni kelatoterapeutici. Zbog svojih kelirajućih svojstava, osim u farmaceutske svrhe, ti se spojevi dodatno istražuju i u analitičkoj kemiji za ekstrakciju ${ }^{6,8,17,23-25}$ pojedinih metala iz vodenih otopina, pri čemu se sastav nastalih kompleksa i sposobnost keliranja liganda najčešće određuju UV-Vis-spektrofotometrijskim tehnikama.

Prije nego što se određeni kelirajući agens uopće počne razmatrati kao potencijalni kelatoterapeutik ili ekstraktant metala važno je detaljno ispitati njegova fizikalno-kemijska svojstva u otopini. Uz to, potrebno je okarakterizirati nastale kompleksne vrste liganda i promatranog iona, pogotovo one koje prevladavaju pri fiziološkim vrijednostima $\mathrm{pH}$. Njihov udjel i karakter ovisi o koncentracijama iona metala, samog liganda i pH vrijednosti otopine te se za bidentatne 3,4-HP ligande i Fe(III) može opisati sljedećim pojednostavljenim ravnotežnim modelom (shema 6): ${ }^{26}$

$\begin{array}{cc}\mathrm{Fe}^{3+}+\mathrm{L}^{-} \rightleftharpoons \mathrm{FeL}^{2+} & K_{1} \\ \mathrm{FeL}^{2+}+\mathrm{L}^{-} \rightleftharpoons \mathrm{FeL}_{2}^{+} & K_{2} \\ \mathrm{FeL}_{2}^{+}+\mathrm{L}^{-} \rightleftharpoons \mathrm{FeL}_{3} & K_{3} \\ \mathrm{Fe}^{3+}+3 \mathrm{~L}^{-} \rightleftharpoons \mathrm{FeL}_{3} & \beta_{3} \\ \log \beta_{3}=\log K_{1}+\log K_{2}+\log K_{3} & \end{array}$

Shema 6 - Pojedinačne $\left(K_{1}, K_{2}, K_{3}\right)$ i ukupna $\left(\beta_{3}\right)$ konstanta stabilnosti nastajanja kompleksne vrste Fe(III) $: \mathrm{L}=1: 3$

Scheme 6 - Stepwise $\left(K_{1}, K_{2}, K_{3}\right)$ and overall $\left(\beta_{3}\right)$ stability constants for formation of Fe(III): $L=1: 3$ complex species
Prilikom kompleksiranja trovalentnih metalnih kationa s 3,4-HP ligandima pri fiziološkim pH vrijednostima nastaju peteročlani kelatni prstenovi u kojima je metal koordiniran s po dva vicinalna kisikova atoma te prevladavaju nenabijeni kompleksi sastava M(III):3,4-HP $=1: 3$ (slika 3). Koordinacija metalnog iona u tim kompleksima je uglavnom nepravilna oktaedarska. Velikom broju tih kompleksa određena je kristalna i molekulska struktura. ${ }^{4,20,26-29}$

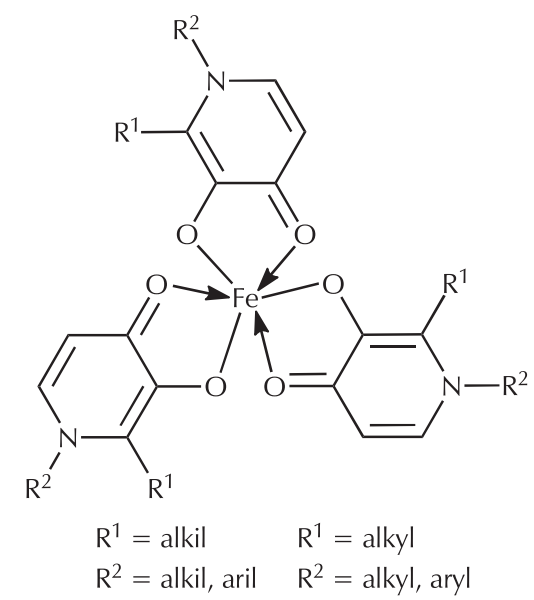

Slika 3 - Općenita strukturna formula kompleksa Fe(III) : 3,4-HP $=1: 3$

Fig. 3 -General structural formula of Fe(III):3,4-HP $=1: 3$ complex

Parametri koji podrobnije opisuju fizikalno-kemijska svojstva nekog potencijalnog kelatora su: ${ }^{1}$

a. vrijednost $p K_{a}$ koja definira kiselo-bazna svojstva liganda;

b. vrijednost $\log P$ odnosno $\log D$ samog liganda kao i njegova kompleksa s metalom. Oba parametra spominju se u literaturi ${ }^{1,3,26}$ i opisuju njihov lipo-hidrofilni karakter koji je iznimno važan jer procjenjuje biodostupnost kelatora te predviđa uklanjanje kompleksa iz organizma. Koeficijent particije $P$ omjer je množinskih koncentracija promatrane vrste (liganda ili kompleksa) nakon njezine razdiobe između dvaju otapala koja se ne miješaju, najčešće oktan-1-ola i puferirane vodene otopine $(\mathrm{pH}=7,4)$. Koeficijent distribucije $D$, za razliku od parametra $P$, mjeri se u kontroliranim uvjetima (termostatirane aparature, stroga kontrola $\mathrm{pH}$ ) i dodatno uzima u obzir sve moguće kiselo-bazne promjene kao i eventualne reakcije disocijacije kompleksa koje bi se mogle odvijati u promatranom sustavu pri spomenutom $\mathrm{pH}$. S obzirom na to da je većina 3,4-HP derivata kao i njihovih kompleksa pri $\mathrm{pH} \approx 7$ u neutralnom obliku i s obzirom na to da se danas u svrhu određivanja tih vrijednosti primjenjuju modernije metode kojima su omogućeni kontrolirani uvjeti, ta se dva parametra za tu vrstu spojeva u novijim literaturnim navodima podrazumijevaju istim. Starije metode koje su se primjenjivale za mjerenje tog parametra su klasično izmućkavanje (engl. shake-flask method), dok se u novije vrijeme upotrebljavaju moderniji ekstraktori te razne modificirane 
automatizirane metode kontinuiranog toka. Lipofilnim ligandima smatraju se derivati 3,4-HP s $\log D>-1$. Kompleksi tih liganada sa željezom u pravilu imaju i do tri puta veću lipofilnost. ${ }^{26} \mathrm{U}$ slučaju hidrofilnih spojeva $(\log D<-1)$ kompleksi zadržavaju slične vrijednosti $\log D$, što sugerira sličnu topljivost jednih i drugih $\mathrm{u}$ fiziološkim uvjetima. Varijacije $\log P(\log D)$ vrijednosti uobičajeno se postižu uvođenjem različitih supstituenata na dušikov atom ( $N$-arilni, $N$-alkilni, $N$-alkilamidni, $N$-alkilkarboksilni, itd.);

c. vrijednost $\log \beta$ (logaritamska vrijednost ukupne konstante stabilnosti kompleksa liganda s određenim metalnim ionom, shema 6) ukazuje na stabilnost kompleksa i selektivnost liganda prema ispitivanom ionu;

d. vrijednost $\mathrm{pM}$ liganda $\left(\mathrm{pM}=-\log \left[\mathrm{M}^{\mathrm{n}+}\right] ;\left[\mathrm{M}^{\mathrm{n}+}\right]=\right.$ koncentracija nekompleksiranog kationa u otopini) parametar je koji omogućuje međusobnu usporedbu različitih liganada s različitim kiselo-baznim profilom i brojem donorskih skupina u njihovoj sposobnosti keliranja određenog kationa. pM se definira za svaki ispitivani ligand u istim uvjetima, konkretno u području fiziološkog pH pri mikromolarnoj množinskoj koncentraciji metala i deset puta većoj množinskoj koncentraciji liganda $\left(c_{\mathrm{L}} / C_{\mathrm{M}}=10, C_{\mathrm{L}}=10^{-5} \mathrm{M}, \mathrm{pH}=7,4\right) .{ }^{30} \mathrm{Vrijed-}$ nosti tog parametra za različite $N$-alkilne i alkilarilne 3,4-HP i sljedeće katione metala iznose pFe $=17-22$, $\mathrm{pAl}=14-16, \mathrm{pGa}=15-21 .^{3}$

Za eksperimentalno određivanje fizikalno-kemijskih parametara najčešće se primjenjuju već spomenute spektrofotometrijske tehnike, koje se po potrebi ovisno o parametru koji se određuje dodatno kombiniraju potenciometrijskim mjerenjima. Rai $i$ sur. ${ }^{26}$ proveli su jedno takvo opširno istraživanje fizikalno-kemijskih parametara serije $\mathrm{N}$-alkil supstituiranih 2-alkil-3,4-HP derivata koji su dijelom bili literaturno poznati, a neki od njih su za potrebe tog istraživanja pripravljeni Harrisovom metodom iz maltola odnosno etil-maltola i odgovarajućih aminskih derivata. Spojevima su određene vrijednosti $\mathrm{p} K_{\mathrm{a}}$ a kompleksima $\mathrm{s}$ $\mathrm{Fe}(\mathrm{III})$ konstante stabilnosti. Lipofilniji derivati dobiveni su uvođenjem duljih alkilnih lanaca na dušikov atom, što je rezultiralo očekivanim povećanjem vrijednosti $\log D$ kako liganada tako i njihovih kompleksa.

Kao primjer ispitivanja fizikalno-kemijskih svojstava $\mathrm{N}$-arilnih 3,4-HP derivata, spomenuli bismo istraživanje provedeno u zavodima za organsku, analitičku i fizikalnu kemiju, Prirodoslovno-matematičkog fakulteta na 1-(p-aminofenil)-3-hidroksi-2-metilpiridin-4-onu (shema $2 \mathrm{~b}, \mathrm{R}^{1}=\mathrm{NH}_{2}$, $\mathrm{R}^{2}=\mathrm{CH}_{3}, \mathrm{R}^{3}=\mathrm{H}$ ), koji je ujedno preliminarno ispitan $\mathrm{i}$ kao potencijalni ekstraktant za Fe(III). ${ }^{8}$ Navedeni derivat je u tu svrhu pripravljen izravnom metodom bez dodatka katalizatora u prinosu od $42 \%$. Kiselo-bazna svojstva spoja određena su spektrofotometrijsko-potenciometrijskim titracijama. Konstante protoniranja bile su sljedeće: 2,96 za protoniranje karbonilnog kisikova atoma, 5,60 za protoniranje amino-skupine fenilnog prstena i 9,75 za deprotoniranje hidroksilne skupine piridinonskog prstena. Dodatno, određene su logaritamske vrijednosti ukupnih konstanti stabilnosti $(\log \beta)$ pri različitim vrijednostima $\mathrm{pH}$ te ionskoj jakosti $\left(\mathrm{NaCl}, I_{\mathrm{c}}=0,1 \mathrm{moldm}^{-3}, t=25{ }^{\circ} \mathrm{C}\right) \mathrm{za}$ nastale protonirane i deprotonirane kompleksne vrste. Vrijednost $\log \beta_{3}$ za stvaranje kompleksa Fe(III) : p-aminofenil
3,4-HP = $1: 3$, koji prevladava u području pH $6-8$, iznosi 34,8 što je u skladu s literaturnim vrijednostima ${ }^{4}$ sličnih derivata za tu kompleksnu vrstu. Dodatno se pokazalo da taj 3,4-HP derivat može poslužiti kao potencijalni ekstraktant za Fe(III) te je utvrđeno da je $\mathrm{pH}=6$ optimalan za ekstrakciju dominantne kompleksne vrste iz vodene u organsku fazu. Učinkovitost provedene ekstrakcije iznosila je $95 \%$.

U novijoj literaturi postoji nekoliko metoda in silico koje olakšavaju i ubrzavaju fizikalno-kemijsku karakterizaciju pripravljenih liganada odnosno njihovih kompleksa s promatranim ionom metala, koje mogu biti dodatna pomoć pri dizajnu novih potencijalnih kelatora. Skupina autora ${ }^{31}$ pod mentorstvom Roberta C. Hidera, professora emeritusa medicinske kemije na King's College u Londonu, koji se smatra jednim od pionira piridinonske kemije, primijenila je kvantnomehaničke račune i semiempirijske metode za određivanje $\mathrm{p} K_{\mathrm{a}}$ hidroksilnih skupina serije od $48 \mathrm{~N}$-alkil supstituiranih 3,4-HP derivata. Dobivene vrijednosti uspoređene su s literaturnim i/ili eksperimentalno određenim vrijednostima $\mathrm{p} K_{\mathrm{a}}$. Pokazalo se da je ispitani kvantnomehanički model (B3LYP/6-31+G(d)/CPCM, Paulingov radijus, otapalo: voda) iznimno točan te da su odstupanja uglavnom unutar intervala $\pm 0,2 \log$ jedinice. Primjerice, 8,79 i 8,81 su eksperimentalna i predviđena $p K_{a}$-vrijednost hidroksilne skupine deferiprona. Ista grupa autora pokazala je da taj model ima veliki potencijal u predviđanju pojedinačne konstante stabilnosti $\left(\log K_{1}\right)$ za nastajanje kompleksa 1:1 tih derivata i Fe(III). Eksperimentalne i računalne vrijednosti bile su strogo korelirane (točnost unutar intervala $\pm 0,32 \log$ jedinice). ${ }^{32}$

$\cup$ odnosu na njihove analoge, derivate 3-hidroksipiran-4-ona, 3,4-HP se prilikom keliranja kationa metala ponašaju kao jače Lewisove baze, što se objašnjava učinkovitijom delokalizacijom naboja unutar prstena kao posljedica razlike u elektronegativnosti heteroatoma. Delokalizacija elektronskog para s dušikova atoma u prstenu prema karbonilnom kisikovom atomu utječe na bazičnost i elektronsku gustoću kelirajućeg veznog mjesta te samim time i na selektivnost tih spojeva prema navedenim tvrdim ionskim vrstama. Te tvrdnje dodatno su potvrđene kristalografskim analizama kojima se pokazalo da je vrijednost duljine veze u karbonilnoj skupini veća od uobičajene, što znači da karbonilni kisikov atom piridinonskog skeleta ima izraženiji alkoksidni karakter. ${ }^{33} \mathrm{U}$ području kiselog $\mathrm{pH}$ ne dolazi do protoniranja piridinonskog dušikovog atoma, već se protonira kisik karbonilne skupine, što je također potvrđeno kristalografskim metodama ali i semiempirijskim računima. Primjerice, kod obaju protoniranih oblika deferiprona iznosi energija za protoniranje dušikova i kisikova atoma jasno se razlikuju i iznose redom $+69,9 \mathrm{kcal} \mathrm{mol}^{-1}$ $\mathrm{i}+39,5 \mathrm{kcal} \mathrm{mol}^{-1}$. $^{34}$ Kao što se može vidjeti iz sheme 7, vrijednosti $\mathrm{p} K_{\mathrm{a}}$ piridinonskog skeleta su za većinu $N$-alkilnih i N-arilnih 3,4-HP derivata vrlo slične bez obzira na vrstu supstituenta na dušikovu atomu. Drugim riječima, varijacijom supstituenta može se podešavati lipo-hidrofilni karakter, opisan već spomenutim parametrom $\log P$, a pritom ne utjecati značajno na kiselo-bazna svojstva 3,4-HP prstena. Zanimljivo istraživanje u tom kontekstu objavili su Schlindwein $i$ sur. ${ }^{35}$ Pripravljeni su, izolirani i okarakterizirani kompleksi Fe(III) :3,4-HP $=1: 3$ u čvrstom stanju i u otopini za nekoliko različitih $\mathrm{N}$-aril supstituiranih $3,4-\mathrm{HP}$ 
derivata. Trodimenzijske strukture kompleksa određene su proširenom finostrukturnom spektroskopijom rendgenske apsorpcije (krat. EXAFS, engl. Extended X-Ray Absorption Fine Structure). Pokazalo se da je struktura tih kompleksa u čvrstom stanju uglavnom zadržana i u otopini te da varijacije u lipofilnosti liganda ne utječu bitno na njegovu sposobnost keliranja željeza.<smiles>[R]c1c(O)c(O)cc[n+]1[R]</smiles><smiles>[R]c1c(O)c(=O)ccn1[R]</smiles><smiles>[R]c1c([O-])c(=O)ccn1[R]</smiles>

$$
\begin{array}{ll}
\mathrm{R}^{1}=\text { alkil } & \mathrm{R}^{1}=\text { alkyl } \\
\mathrm{R}^{2}=\text { alkil, aril } & \mathrm{R}^{2}=\text { alkyl, aryl }
\end{array}
$$

Shema 7 - Rezonantni oblici protoniranih i deprotoniranih vrsta derivata $3,4-\mathrm{HP}^{33}$

Scheme 7 - Resonance forms of protonated and deprotonated species of 3,4-HP derivatives ${ }^{33}$

\section{Zaključak}

Heterociklički derivati 3,4-HP svestrani su biološki agensi ponajprije zahvaljujući svojoj sposobnosti keliranja trovalentnih metalnih kationa. U fiziološkim uvjetima imaju izrazito visok afinitet za Fe(III), te se stoga najviše ispituju za liječenje bolesti koje rezultiraju prekomjerenim nakupljanjem toga metala u organizmu. $U$ literaturi su najviše zastupljene dvije metode za sintezu osnovnog 3,4-HP skeleta, Harrisova metoda i sinteza izravnim pristupom. Uvođenjem različitih supstituenata na dušikov atom piridinonskog prstena može se mijenjati njihov lipo-hidrofilni karakter bez utjecaja na kelirajuće vezno mjesto. Iz fizikalno-kemijskih parametara tih derivata, osobito $\log P, \mathrm{p} K_{\mathrm{a}} \mathrm{i}$ pM za razne katione metala, može se zaključiti da, osim što izvrsno i selektivno keliraju trovalentne metalne katione, mogu imati i zadovoljavajuću biodostupnost. U području fiziološkog pH ti bidentatni ligandi stvaraju neutralne komplekse koji se lako mogu eliminirati iz organizma.

\section{ZAHVALA}

Autorice se posebno zahvaljuju Hrvatskoj zakladi za znanost za potporu ovoga rada u sklopu projekta IP-2014-097899 Sinteza, strukturna analiza i biološka evaluacija peptidomimetika i glikokonjugata.

$$
\begin{aligned}
& \text { Popis kratica i simbola } \\
& \text { List of abbreviations and symbols } \\
& \text { Bn - benzil } \\
& \text { - benzyl } \\
& \text { DFO - desferioksamin B } \\
& \text { - desferrioxamine B } \\
& \text { EXAFS - proširena fino strukturna spektroskopija } \\
& \text { rendgenske apsorpcije } \\
& \text { - extended X-ray absorption fine structure } \\
& \text { HP - hidroksipiridinoni } \\
& \text { - hydroxypyridinones } \\
& p \text {-TsOH }-p \text {-toluensulfonska kiselina } \\
& \text { - } p \text {-toluenesulfonic acid } \\
& \text { D } \quad \text { - koeficijent distribucije } \\
& \text { - distribution coefficient } \\
& I_{\mathrm{c}} \quad \text { - ionska jakost } \\
& \text { - ionic strength } \\
& \text { K - ravnotežna konstanta } \\
& \text { - equilibrium constant } \\
& P \quad \text { - koeficijent particije (razdiobe) } \\
& \text { - partition coefficient } \\
& \text { - vrijeme, h } \\
& \text { - time, h } \\
& \text { V } \quad \text { - obujam } \\
& \text { - volume } \\
& \beta \quad-\text { ukupna konstanta stabilnosti kompleksa } \\
& \text { - overall stability constant of complex }
\end{aligned}
$$

\section{Literatura \\ References}

1. M. A. Santos, S. Chaves, 3-Hydroxypyridinone derivatives as metal sequestering agents for therapeutic use, Future Med. Chem. 7 (2015) 383-410, doi: http://dx.doi.org/10.4155/ fmc.14.162.

2. W. Kandioller, A. Kurzwernhart, M. Hanif, S. M. Meier, H. Henke, B. K. Keppler, C. G. Hartinger, Pyrone derivatives and metals: From natural products to metal-based drugs, J. Organomet. Chem. 696 (2011) 999-1010, doi: http://dx.doi. org/10.1016/j.jorganchem.2010.11.010.

3. M. A. Santos, S. M. Marques, S. Chaves, Hydroxypyridinones as "privileged" chelating structures for the design of medicinal drugs, Coord. Chem. Rev. 256 (2012) 240-259, doi: 
http://dx.doi.org/ 10.1016/j.ccr.2011.08.008.

4. P. S. Dobbin, R. C. Hider, Iron chelation therapy, Chem. Brit. (1990) 565-567.

5. Ž. Car, T. Hrenar, V. Petrović Peroković, R. Ribić, M. Seničar, S. Tomić, Mannosylated N-aryl substituted 3-hydroxypyridine-4-ones: Synthesis, hemagglutination inhibitory properties and molecular modeling, Chem. Biol. Drug Des. 84 (2014) 393-401, doi: http://dx.doi.org/10.1111/cbdd.12329.

6. V. Petrović Peroković, A. Gojmerac Ivšić, Ž. Car, S. Tomić, Synthesis of 3-hydroxy-1-(p-methoxyphenyl)-2-methylpyridine-4-one and spectrophotometric extraction studies on its complexation of vanadium(V), Croat. Chem. Acta 87 (2014) 103-109, doi: http://dx.doi.org/10.5562/cca2366.

7. V. Petrović Peroković, B. Prugovečki, Ž. Car, Synthesis, crystal and molecular structure of novel adamantyl derivatives of $\mathrm{N}$-aryl substituted 3-hydroxy-2-methylpyridine-4-ones, Croat. Chem. Acta 86 (2013) 317-323, doi: http://dx.doi. org/10.5562/cca2339.

8. A. Gojmerac Ivšić, V. Tomišić, Ž. Car, B. Prugovečki, S. Tomić, Synthesis and characterization of a new 4-pyridone derivative and its complexation of iron(III), J. Mol. Str. 990 (2011) 237-243, doi: http://dx.doi.org/10.1016/j.molstruc.2011.01.051.

9. R. L. N. Harris, Potential wool growth inhibitors. Improved syntheses of mimosine and related 4(1H)-Pyridones, Aust. J. Chem. 29 (1976) 1329-1334, doi: http://dx.doi.org/10.1071/ $\mathrm{CH} 9761329$.

10. M. Färber, H. Osiander, T. Severin, Synthesis of N-substituted 3-hydroxy-2-methyl-4-pyridones and -pyridonimines, 31 (1994) 947-956, doi: http://dx.doi.org/10.1002/ jhet. 5570310443 .

11. W. O. Nelson, T. B. Karpishin, S. J. Rettig, C. Orvig, Physical and structural studies of N-substituted-3-hydroxy-2-methyl-4(1H)-pyridinones, Can. J. Chem. 66 (1988) 123-131, doi: http://dx.doi.org/10.1139/v88-019.

12. M. A. Santos, M. Gil, S. Marques, L. Gano, G. Cantinho, S. Chaves, N-Carboxyalkyl derivatives of 3-hydroxy-4-pyridinones: Synthesis, complexation with Fe(III), $\mathrm{Al}(\mathrm{III})$ and $\mathrm{Ga}(\mathrm{III})$ and in vivo evaluation, J. Inorg. Biochem. 92 (2002) 43-54, doi: http://dx.doi.org/10.1016/S0162-0134(02)00483-X.

13. L. E. Scott, M. Telpoukhovskaia, C. Rodríguez-Rodríguez, M. Merkel, M. L. Bowen, B. D. G. Page, D. E. Green, T. Storr, F. Thomas, D. D. Allen, P. R. Lockman, B. O. Patrick, M. J. Adam, C. Orvig, N-Aryl-substituted 3-( $\beta$-D-glucopyranosyloxy)-2-methyl-4(1H)-pyridinones as agents for Alzheimer's therapy, Chem. Sci. 2 (2011) 642-648, doi: http://dx.doi. org/10.1039/COSC00544D.

14. L. Saghaie, H. Sadeghi-Aliabadi, M. Kafiri, Synthesis and biological evaluation of bidentate 3-hydroxypyridin-4-ones iron chelating agents, Res. Pharm. Sci. 6 (2011) 117-122.

15. D. E. Green, C. L. Ferreira, R. V. Stick, B. O. Patrick, M. J. Adam, C. Orvig, Carbohydrate-bearing 3-hydroxy-4-pyridinonato complexes of gallium(III) and indium(III), Bioconjugate Chem. 16 (2005) 1597-1609, doi: http://dx.doi.org/ 10.1021/bc0501808.

16. L. Saghaie, R. C. Hider, Synthesis and physico-chemical properties of a series of bidentate 3-hydroxypyridin-4-ones iron chelating agents, Res. Pharm. Sci. 3 (2008) 21-30.

17. K. Jakopčić, B. Tamhina, F. Zorko, M. J. Herak, Synthesis and physical properties of some new 4-pyridone extractants, J. Inorg. Nucl. Chem. 39 (1977) 1201-1203, doi: http://dx.doi. org/10.1016/0022-1902(77)80345-X.

18. L. Saghaie, M. Mirmohammad Sadeghi, A. Nikazma, Synthesis, analysis and determination of partition coefficients of $\mathrm{N}$-arylhydroxypyridinone derivatives as iron chelators, Res.
Pharm. Sci. 1 (2006) 40-48.

19. A. Fassihi, D. Abedi, L. Saghaie, R. Sabet, H. Fazeli, G. Bostaki, O. Deilami, H. Sadinpour, Synthesis, antimicrobial evaluation and QSAR study of some 3-hydroxypyridine-4-one and 3-hydroxypyran-4-one derivatives, Eur. J. Med. Chem. 44 (2009) 2145-2157, doi: http://dx.doi.org/10.1016/j.ejmech.2008.10.022.

20. Z. Zhang, S. J. Rettig, C. Orvig, Lipophilic coordination compounds: aluminum, gallium, and indium complexes of 1-aryl3-hydroxy-2-methyl-4-pyridinones, Inorg. Chem. 30 (1991) 509-515, doi: http://dx.doi.org/10.1021/ic00003a031.

21. R. J. C. Kleipool, J. P. Wibaut, The preparation of some 3-hydroxy-4-pyridones substituted on the nitrogen atom, Rec. Trav. Chim. Pays-Bas 69 (1950) 1041-1047, doi: http://dx. doi.org/10.1002/recl.19500690813.

22. C. Queiros, M. J. Amorim, A. Leite, M. Ferreira, P. Gameiro, B. Castro, K. Biernacki, A. Magalhães, J. Burgess, M. Rangel, Nickel(II) and cobalt(II) 3-hydroxy-4-pyridinone complexes: Synthesis, characterization and speciation studies in aqueous solution, Eur. J. Inorg. Chem. 2011 (1) (2011) 131-140, doi: http://dx.doi.org/10.1002/ejic.201000849.

23. M. Tsuchya, K. Kohata, T. Odashima, H. Ishii, Solvent extraction of gallium(III) and indium(III) with 1-(4-ethylphenyl)-3-hydroxy- and 1-(4-ethylphenyl)-3-hydroxy-2-methyl-4-pyridones, Anal. Sci. 11 (1995) 343-347, doi: http:// dx.doi.org/10.2116/analsci.11.343.

24. B. Tamhina, K. Jakopčić, F. Zorko, M. J. Herak, Synthesis and physical properties of new 4-pyridone extractants, J. Inorg. Nucl. Chem. 36 (1974) 1855-1857, doi: http://dx.doi. org/10.1016/0022-1902(74)80524-5.

25. V. Vojković, I. Juranović, B. Tamhina, Extraction and separation of germanium(IV) with 4-pyridone derivatives, Croat. Chem. Acta 74 (2001) 467-477.

26. B. L. Rai, L. S. Dekhordi, H. Khodr, Y. Jin, Z. Liu, R. C. Hider, Synthesis, Physicochemical Properties, and Evaluation of N-Substituted-2-alkyl-3-hydroxy-4(1H)-pyridinones, J. Med. Chem. 41 (1998) 3347-3359, doi: http://dx.doi.org/10.1021/ jm9707784.

27. A. Puglisi, J. Spencer, V. Oliveri, G. Vecchio, X. Kong, J. Clarked, J. Milton, Synthesis, physicochemical properties and antioxidant activity of deferiprone-cyclodextrin conjugates and their iron(III) complexes, Dalton Trans. 41 (10) (2012) 2877-2883, doi: http://dx.doi.org/10.1039/c1dt11677k.

28. P. V. Bernhardt, Coordination chemistry and biology of chelators for the treatment of iron overload disorders, Dalton Trans. 37 (30) (2007) 3214-3220, doi: http://dx.doi. org/10.1039/b708133b.

29. T. Zhou, R. C. Hider, X. Kong, Mode of iron(III) chelation by hexadentate hydroxypyridinones, Chem. Commun. 51 (2015) 5614-5617, doi: http://dx.doi.org/10.1039/ c4cc10339d.

30. W. R. Harris, K. N. Raymond, F. L.Weitl, Ferric ion sequestering agents. 6. The spectrophotometric and potentiometric evaluation of sulfonated tricatecholate ligands, J. Am. Chem. Soc. 103 (1981) 2667-2675, doi: http://dx.doi.org/10.1021/ ja00400a030.

31. Y.-L. Chen, D. J. Barlow, X.-Le Kong, Y.-M. Ma, R. C. Hider, Prediction of 3 hydroxypyridin-4-one (HPO) hydroxyl pKa values, Dalton Trans. 41 (21) (2012) 6549-6557, doi: http:// dx.doi.org/10.1039/C2DT12396G.

32. Y.-L. Chen, D. J. Barlow, X.-Le Kong, Y.-M. Ma, R. C. Hider, Prediction of 3-hydroxypyridin-4-one (HPO) log K1 values for Fe(III), Dalton Trans. 41 (2012) 10784-10791, doi: http:// dx.doi.org/10.1039/C2DT31254A.

33. L. E. Scott, C. Orvig, Medicinal inorganic chemistry ap- 
proaches to passivation and removal of aberrant metal ions in disease, Chem. Rev. 109 (2009) 4885-4910, doi: http:// dx.doi.org/10.1021/cr9000176.

34. V. M. Nurchi, G. Crisponi, T. Pivetta, M. Donatoni, M. Remelli, Potentiometric, spectrophotometric and calorimetric study on iron(III) and copper(II) complexes with 1,2-dimethyl-3-hydroxy-4-pyridinone, J. Inorg. Biochem. 102
(2008) 684-692, doi: http://dx.doi.org/doi:10.1016/j.jinorgbio.2007.10.012.

35. W. Schlindwein, E. Waltham, J. Burgess, N. Binsted, A. Nunes, A. Leite, M. Rangel, New lipophilic 3-hydroxy-4-pyridinonate iron(III) complexes: synthesis and EXAFS structural characterisation, Dalton Trans. 36 (10) (2006) 1313-1321, doi: http://dx.doi.org/10.1039/B509671E.

\section{SUMMARY}

\section{3-Hydroxypyridin-4-ones (Part I): Preparation and Chelation Ability \\ Željka Car, Vesna Petrović Peroković, and Srđanka Tomić Pisarović}

Since the discovery of deferiprone in 1982, so far the only 3-hydroxypyridin-4-one chelator for hard metal ions that is clinically approved, these heterocyclic derivatives have become an intensively studied group of compounds. This review presents the two most common synthetic methods used for the preparation of the heterocyclic 3-hydroxypyridin-4-one structure, the Harris method and the direct procedure, as well as the most important physical and chemical parameters needed for the preliminary evaluation of their chelating abilities.

\section{Keywords}

3-hydroxypyridin-4-ones, direct synthesis, Harris method, iron(III), chelating agent, physical and chemical properties

Division of Organic Chemistry, Department of

Review Chemistry, Faculty of Science, University of Zagreb, Horvatovac 102A, HR-10 000 Zagreb, Croatia

Received December 15, 2015 Accepted February 1, 2016 